International Journal of Polymeric Materials, 54:917-931, 2005

Copyright (C) Taylor \& Francis Inc.

ISSN: 0091-4037 print/1563-5333 online

DOI: $10.1080 / 00914030590968943$

\title{
Studies on Thermoplastic Elastomer Based on Linear Low-Density Polyethylene and Latex Product Waste Modified with Thiocarbanilide
}

\section{S. Rajalekshmi \\ Rani Joseph}

Department of Polymer Science and Rubber Technology, Cochin

University of Science and Technology, Cochin, Kerala, India

Latex waste like glove waste was effectively modified using a new reclaiming agent, thiocarbanilide. This modified waste was blended with linear low-density polyethylene (LLDPE) to develop a novel thermoplastic elastomer. Both uncrosslinked and dynamically crosslinked blends were prepared and their properties were studied. The results were found to be comparable to those of conventional thermoplastic elastomers.

Keywords: glove waste, LLDPE, thiocarbanilide, mechanical properties, rheology

\section{INTRODUCTION}

Waste polymer materials have been the biggest threat to the environment in recent years. The most effective solution for this problem is to recycle and reuse the polymer products after their useful life. This has been practiced by the rubber industry by many years, almost entirely by conversion of the waste products to reclaimed rubber [1-6]. Reclaiming process imparts the necessary degree of plasticity to the vulcanized rubber and thereby enabling it to be blended with other polymers [7-10]. Reclaiming process is not exactly devulcanization. The combined sulphur still present after reclaiming is evidence for this. Reclaiming

Received 30 April 2001; in final form 10 May 2001.

The authors remain grateful to the Department of Science and Technology for financial assistance.

Address correspondence to Rani Joseph, Department of Polymer Science and Rubber Technology, Cochin University of Science and Technology, Cochin 682 022, Kerala, India. E-mail: rani@cusat.ac.in 
TABLE 1 Formulation for Modified Waste

\begin{tabular}{lr}
\hline Ingredients & phr \\
\hline Glove waste & 100 \\
NR & 20 \\
ZnO & 5 \\
Stearic acid & 2 \\
Thiocarbanilide & 3 \\
CBS & 0.6 \\
Naphthenic oil & 3 \\
Hydroquinone & 0.2 \\
\hline
\end{tabular}

process involves degradation of the vulcanizate structure, induced by chemical and thermal means followed by mechanical working.

The most effective method of utilizing the reclaimed rubber for industrial applications is the blending method. Among various blends, thermoplastic elastomers based on blends of polyolefins are an important family of engineering materials [11-14]. Thermoplastic elastomers have been prepared by members of the Malaysian rubber producer's Research Association by blending natural rubber with crystalline polyolefines such as polyethylene and polypropylene [15] and their properties have also been reported. Further studies in this area have shown that the addition of a small quantity of crosslinking agent during the melt mixing of the polyolefin and elastomer improves the elastomeric properties of the thermoplastic elastomer [16-18]. This dynamic vulcanization has been defined by A. Y. Coran as the process of vulcanizing rubber, during its intimate melt mixing with a nonvulcanizing thermoplastic polymer [19]. This process results in the formation of a particulate vulcanized rubber phase of stable domain morphology during further melt processing.

This study developed a thermoplastic elastomer based on linear lowdensity polyethylene and latex waste modified with thiocarbanilide

TABLE 2 Properties of Modified Waste

\begin{tabular}{lc}
\hline Property & \\
\hline Volatile matter, \% by mass & 0.63 \\
Acetone extract, \% by mass & 5.81 \\
Ash content, \% by mass & 3.22 \\
Rubber hydrocarbon content, \% by mass & 92.84 \\
Free Sulphur content, \% by mass & 0.90 \\
Mooney viscosity & 29.00 \\
Crosslink density (gmol/cc) & $1.9 \times 10^{-3}$ \\
\hline
\end{tabular}


both unvulcanized and dynamically vulcanized. The mechanical and rheological properties of this material were studied and compared with those of polyethylene/natural rubber blends.

\section{EXPERIMENTAL}

\section{Materials}

Linear low-density polyethylene (LLDPE), natural rubber (IS NR-5), powdered glove waste, thiocarbanilide, which was prepared in the laboratory, polymer additives such as zinc oxide, stearic acid, CBS, sulphur, naphthenic oil, and hydroquinone were used.

\section{Preparation of Blends}

First, the latex product waste was modified as per the formulation given in Table 1. The modified glove waste is referred to as GW hereafter. The properties of the modified waste are given Table 2 . Weight

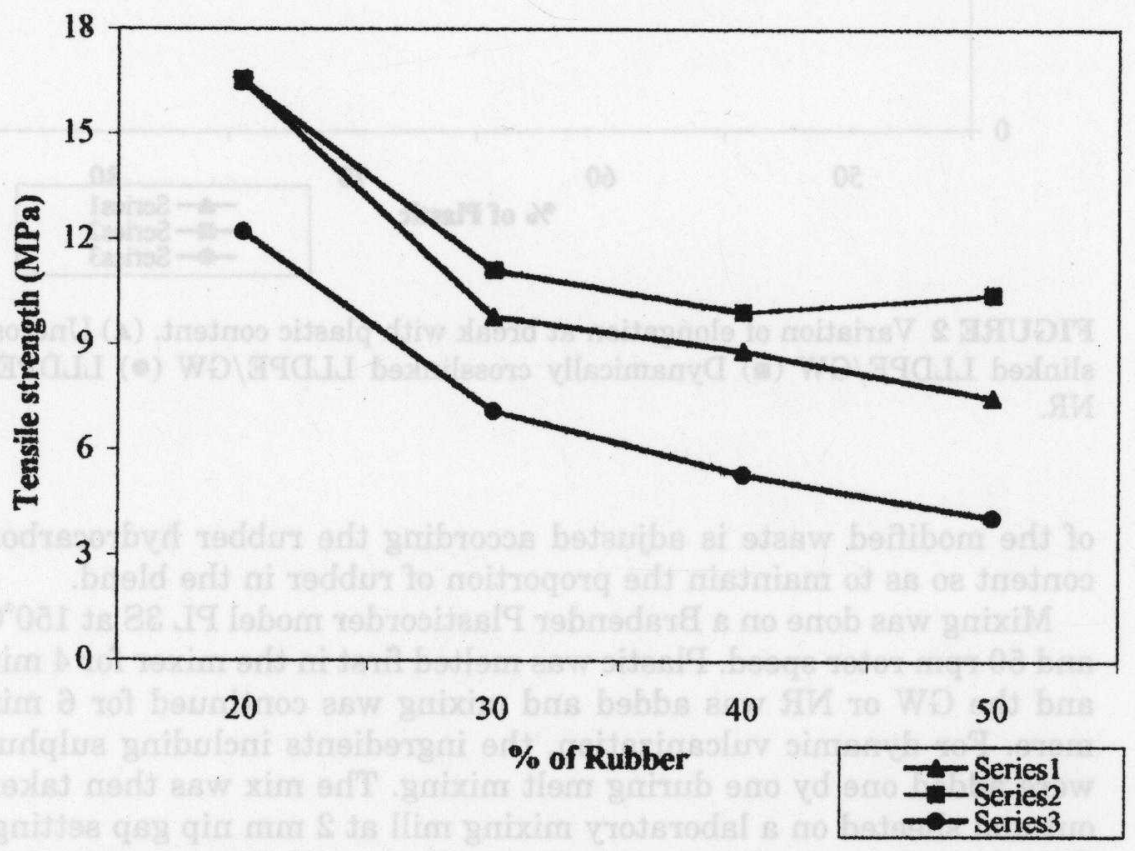

FIGURE 1 Variation of tensile strength with rubber content of LLDPE/ Rubber blends. (৯) Uncrosslinked LLDPE/GW ( Dynamically crosslinked LLDPE/GW (•) LLDPE/NR. 


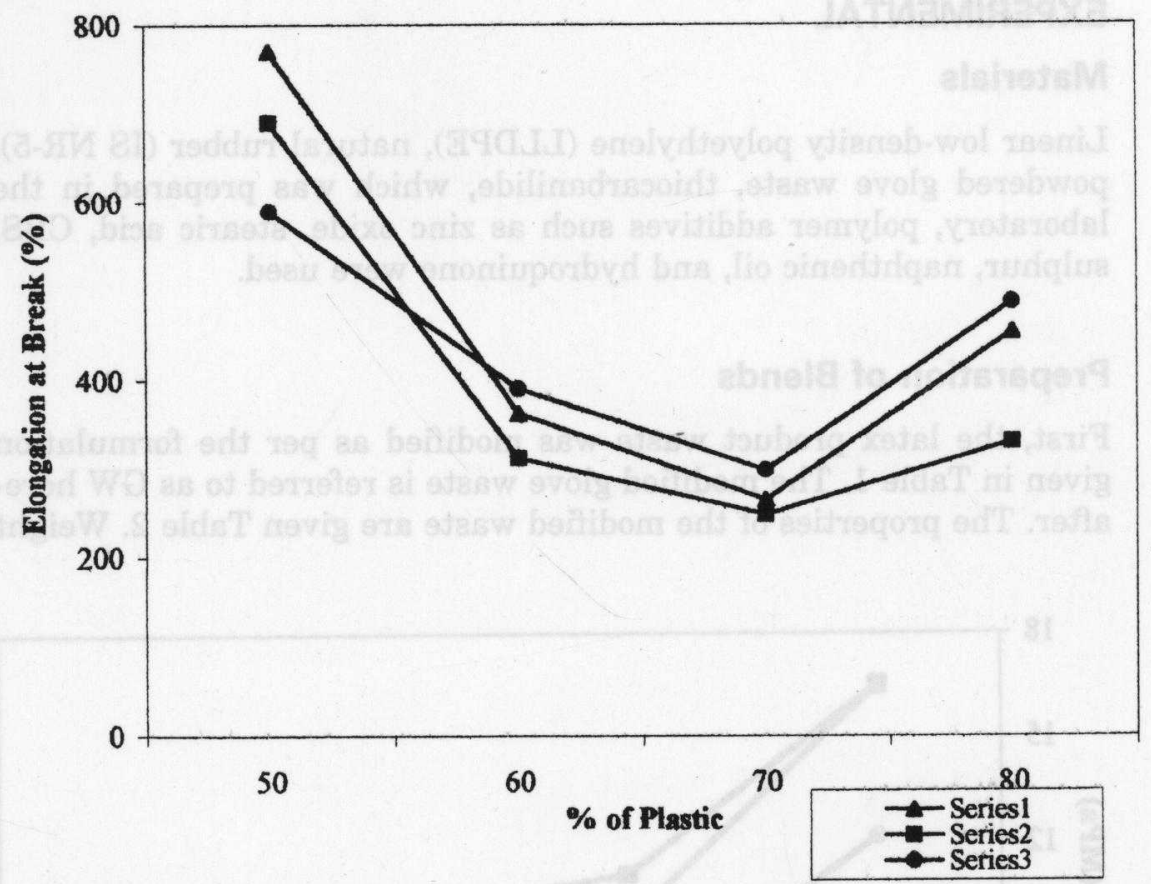

FIGURE 2 Variation of elongation at break with plastic content. (ム) Uncrosslinked LLDPE/GW (•) Dynamically crosslinked LLDPE/GW (•) LLDPE/ NR.

of the modified waste is adjusted according the rubber hydrocarbon content so as to maintain the proportion of rubber in the blend.

Mixing was done on a Brabender Plasticorder model PL $3 \mathrm{~S}$ at $150^{\circ} \mathrm{C}$ and $50 \mathrm{rpm}$ rotor speed. Plastic was melted first in the mixer for $4 \mathrm{~min}$ and the GW or NR was added and mixing was continued for $6 \mathrm{~min}$ more. For dynamic vulcanization, the ingredients including sulphur were added one by one during melt mixing. The mix was then taken out and sheeted on a laboratory mixing mill at $2 \mathrm{~mm}$ nip gap setting. The sheeted material was cut into small pieces and again mixed in the plasticorder for $4 \mathrm{~min}$ so as to get a uniform dispersion of the ingredients. After mixing, the blend was compression molded in an electrically heated hydraulic press at $150^{\circ} \mathrm{C}$ for $6 \mathrm{~min}$. A specially fabricated mold with nuts and bolts was used for this purpose so as to hold the material inside under pressure. The mold with sample was cooled by circulating cold water. Polyester sheets were used in between the mold surfaces to reduce shrink marks on the sheets. 


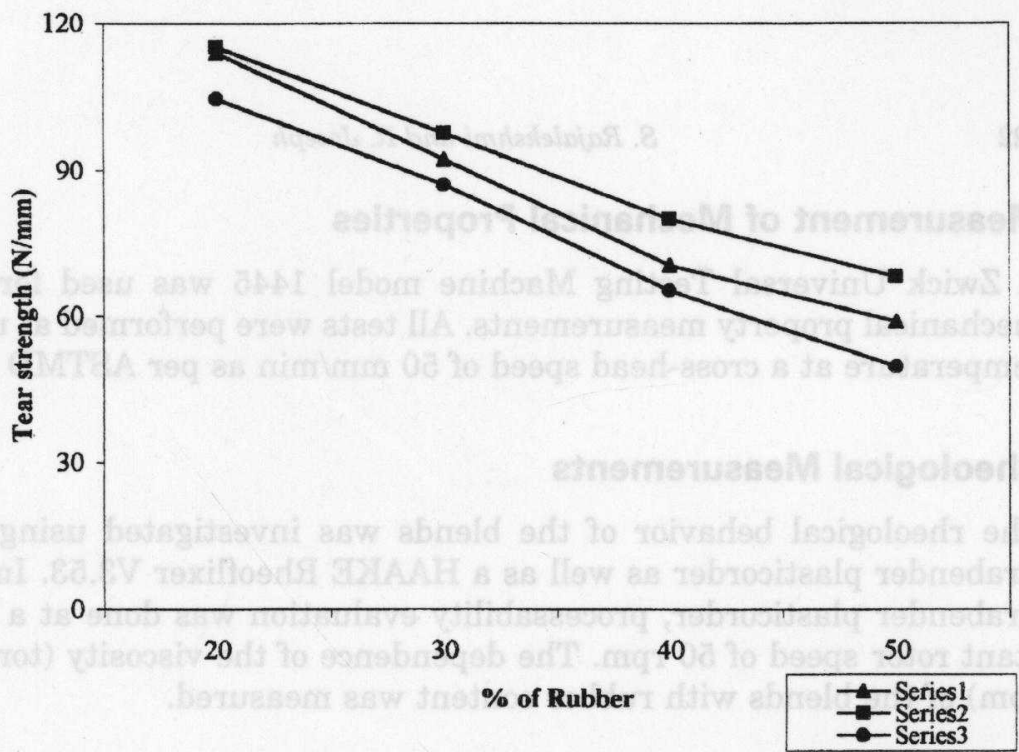

FIGURE 3 Variation of tear strength with rubber content. ( $\Delta$ ) Uncrosslinked LLDPE/GW (₫) Dynamically crosslinked LLDPE/GW (•) LLDPE/NR.

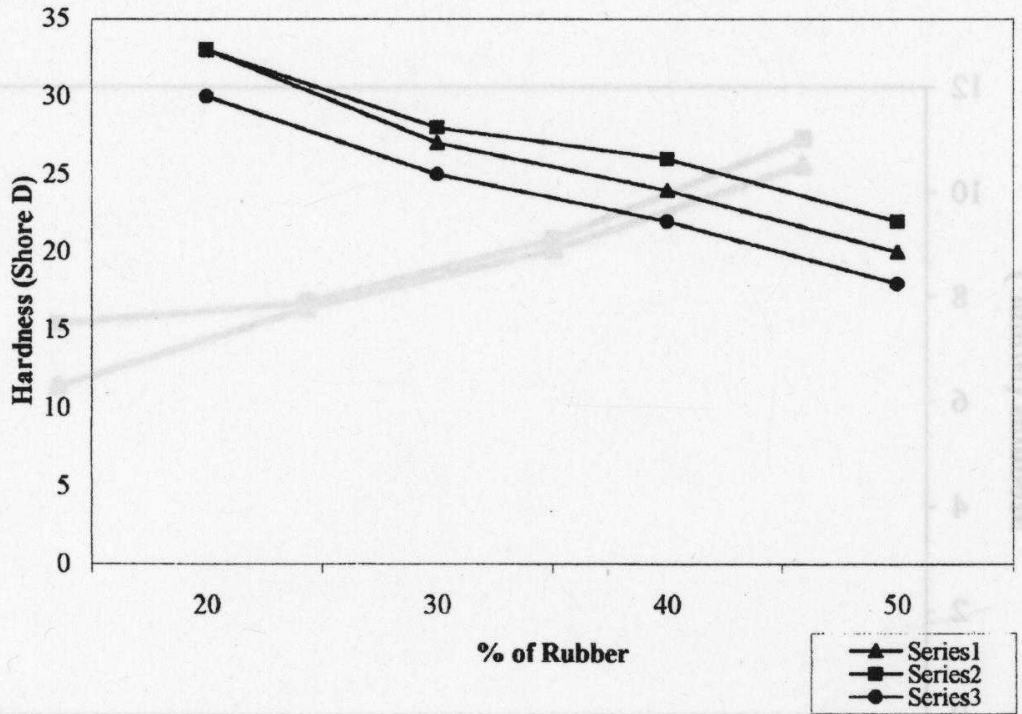

FIGURE 4 Variation of hardness with rubber content. (A) Uncrosslinked LLDPE/GW (•) Dynamically crosslinked LLDPE/GW (•) LLDPE/NR. 


\section{Measurement of Mechanical Properties}

A Zwick Universal Testing Machine model 1445 was used for the mechanical property measurements. All tests were performed at room temperature at a cross-head speed of $50 \mathrm{~mm} / \mathrm{min}$ as per ASTMD 638 .

\section{Rheological Measurements}

The rheological behavior of the blends was investigated using the Brabender plasticorder as well as a HAAKE Rheoflixer V3.53. In the Brabender plasticorder, processability evaluation was done at a constant rotor speed of $50 \mathrm{rpm}$. The dependence of the viscosity (torque/ rpm) of the blends with rubber content was measured.

\section{RESULTS AND DISCUSSION}

Table 1 shows the formulation for the modification of the glove waste and Table 2, the properties of the modified waste.

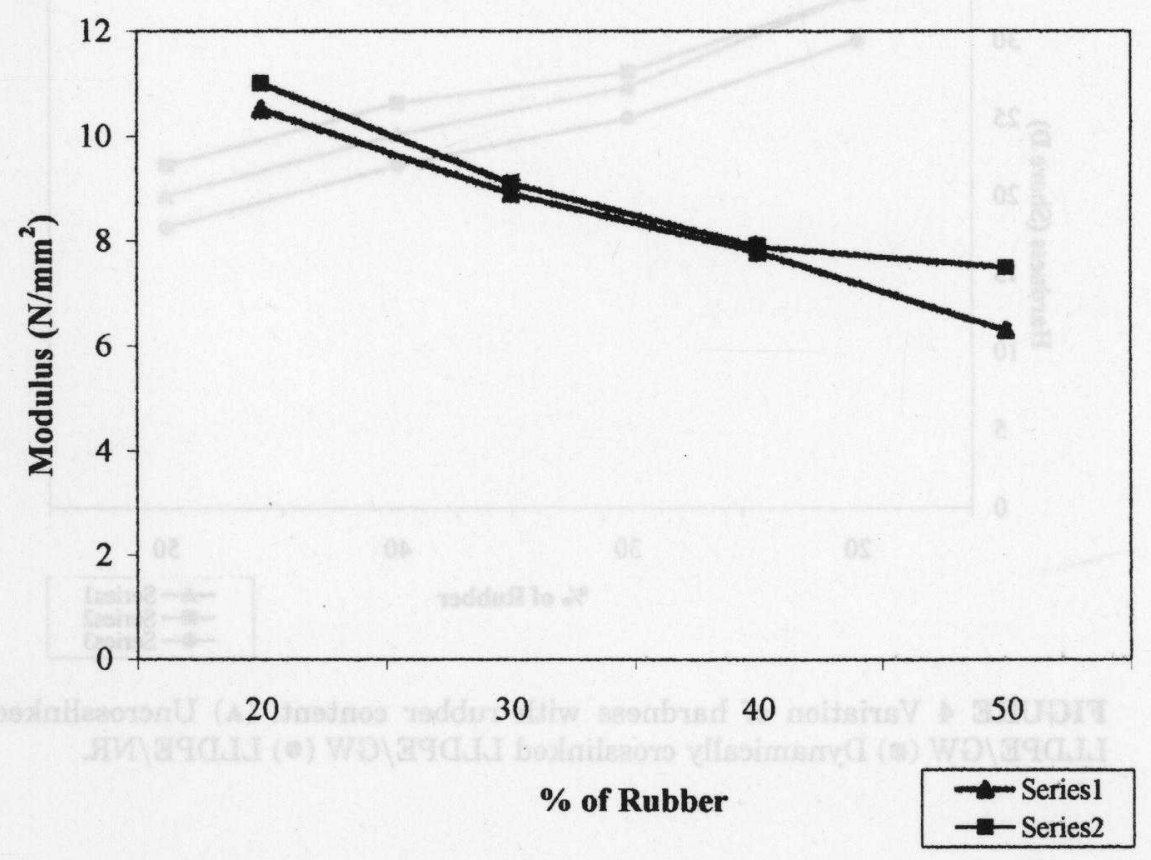

FIGURE 5 Variation of modulus with plastic content. (ム) Uncrosslinked LLDPE/GW (-) Dynamically crosslinked LLDPE/GW. 


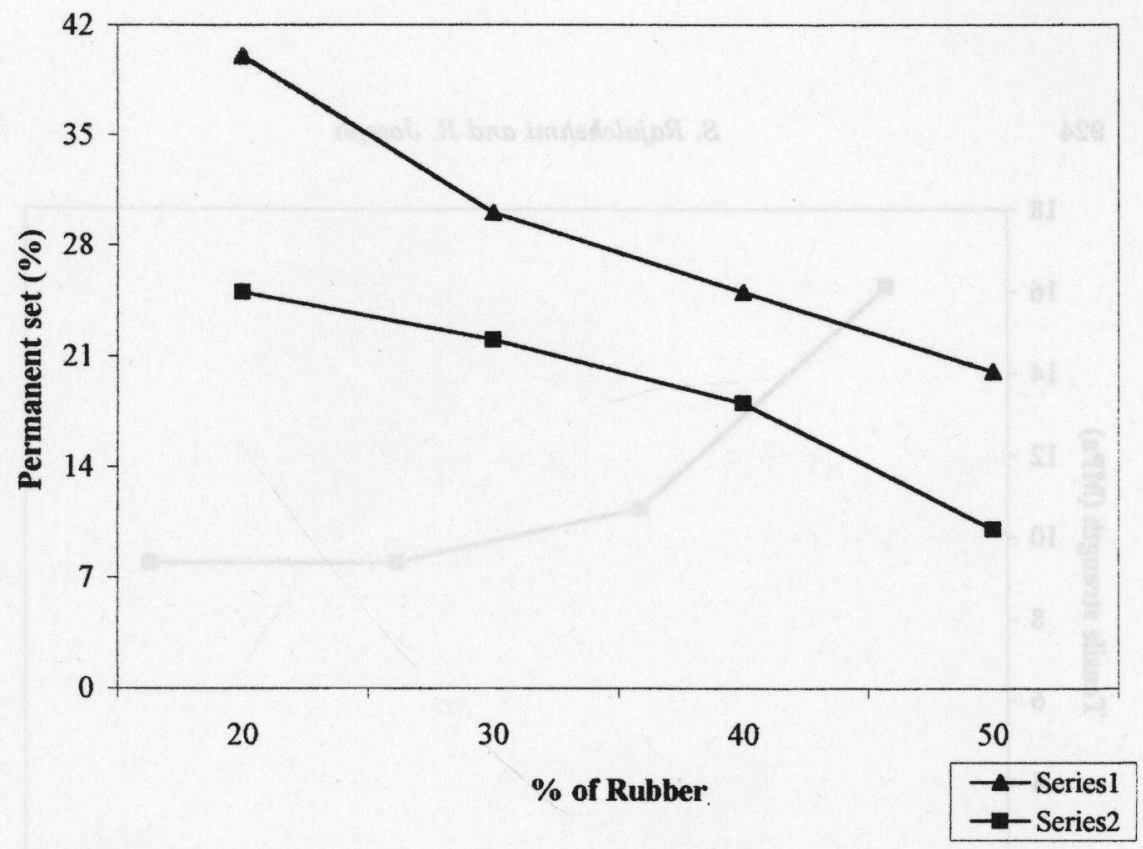

FIGURE 6 Variation of permanent set with rubber content. (A) Uncrosslinked LLDPE/GW ( ) Dynamically crosslinked LLDPE/GW.

Figure 1 shows the variation of tensile strength with rubber content of uncrosslinked and dynamically crosslinked LLDPE/GW and uncrosslinked LLDPE/NR blends. In all the cases tensile strength decreases with increase in the rubber content. LLDPE/GW blends show higher tensile values than LLDPE/NR blends. Also the dynamically vulcanized LLDPE/GW blends show the highest values when compared to unvulcanized blends. The reasons may be the presence of residual crosslinks in GW (crosslink density $1.9 \times 10^{-3}$ ) and also the effect of dynamic vulcanization on mechanical properties [20]. Advantage of dynamic vulcanization is more significant in the 50/50 blend.

Figure 2 shows the variation of elongation at break with plastic content. It can be seen that as the LLDPE content decreases, the elongation at break also decreases [21] up to 60/40 plastic/rubber ratio. At 50/ 50 plastic/rubber ratio a slight increase in the elongation at break is observed. This may be because of the higher proportion of rubber compared to other blends. On dynamic vulcanization of the LLDPE/GW blends, the elongation at break still decreases due to the increase in the extent of crosslinking. 


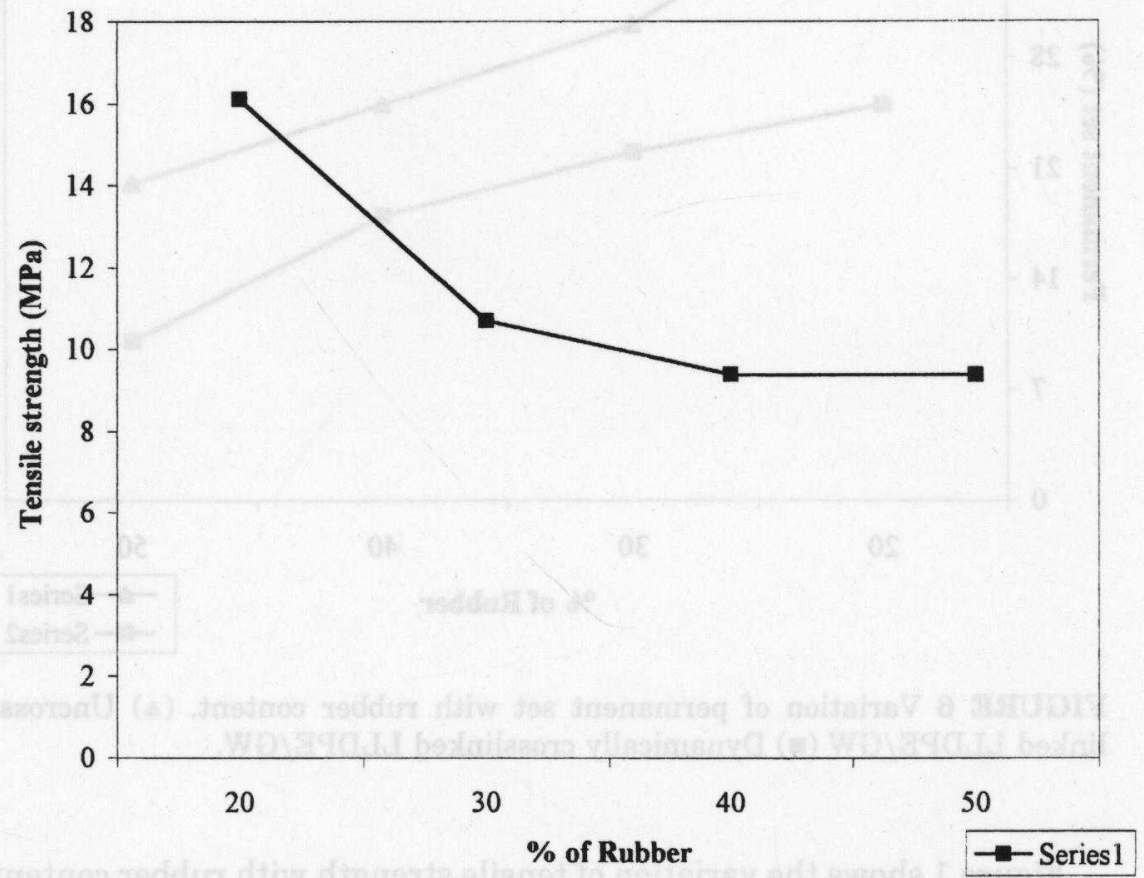

FIGURE 7 Variation of tensile strength with rubber content of dynamically vulcanized, remelted LLDPE/GW. (⿴) Dynamically crosslinked LLDPE/GW.

Figure 3 shows the variation of tear strength with $\%$ of rubber. In all the cases, tear strength decreases with increase in \% of rubber. Both the vulcanized and dynamically vulcanized LLDPE/GW blends show higher tear strength than the LLDPE/NR blends. Again this may be due to the slight crosslinking that is already present in GW. The highest values are exhibited by the dynamically vulcanized blends.

Figure 4 shows the relationship between hardness and \% of rubber. As the rubber content increases, hardness decreases. Owing to the highest extent of crosslinking, the dynamically vulcanized blends of LLDPE/GW exhibit maximum hardness.

In Figure 5 the variation of modulus at $100 \%$ elongation of uncrosslinked and dynamically crosslinked LLDPE/GW blends with plastic content is shown. As the plastic content increases modulus also increases. Slightly higher values are observed for dynamically vulcanized blends.

Figure 6 shows the relationship between permanent set and rubber content of LLDPE/GW blends, both crosslinked and uncrosslinked. 


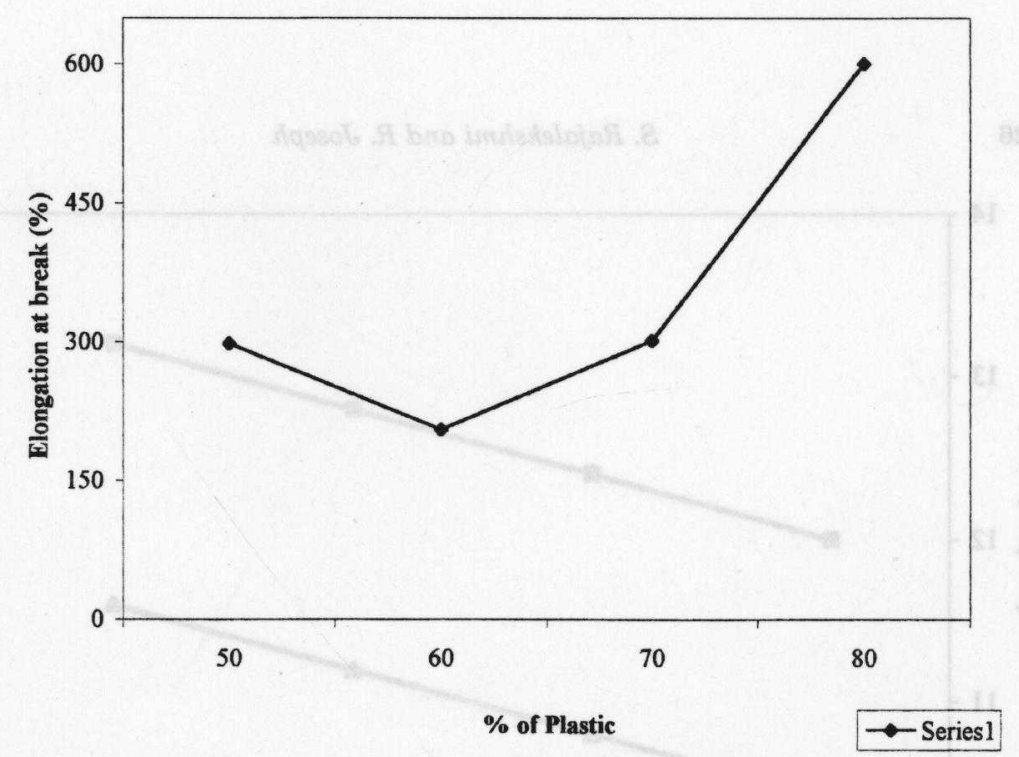

FIGURE 8 Variation of elongation at break with plastic content of dynamically vulcanized, remelted LLDPE/GW. (-) Dynamically crosslinked LLDPE/GW.

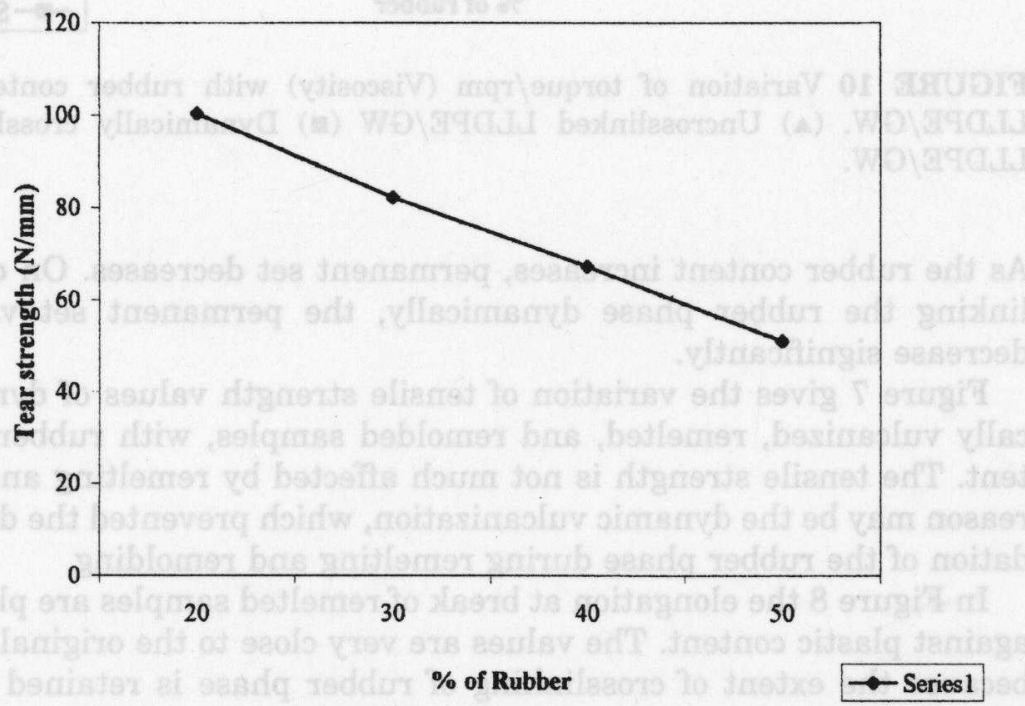

FIGURE 9 Variation of tear strength with rubber content of dynamically vulcanized, remelted LLDPE/GW. ( ) Dynamically crosslinked LLDPE/GW. 


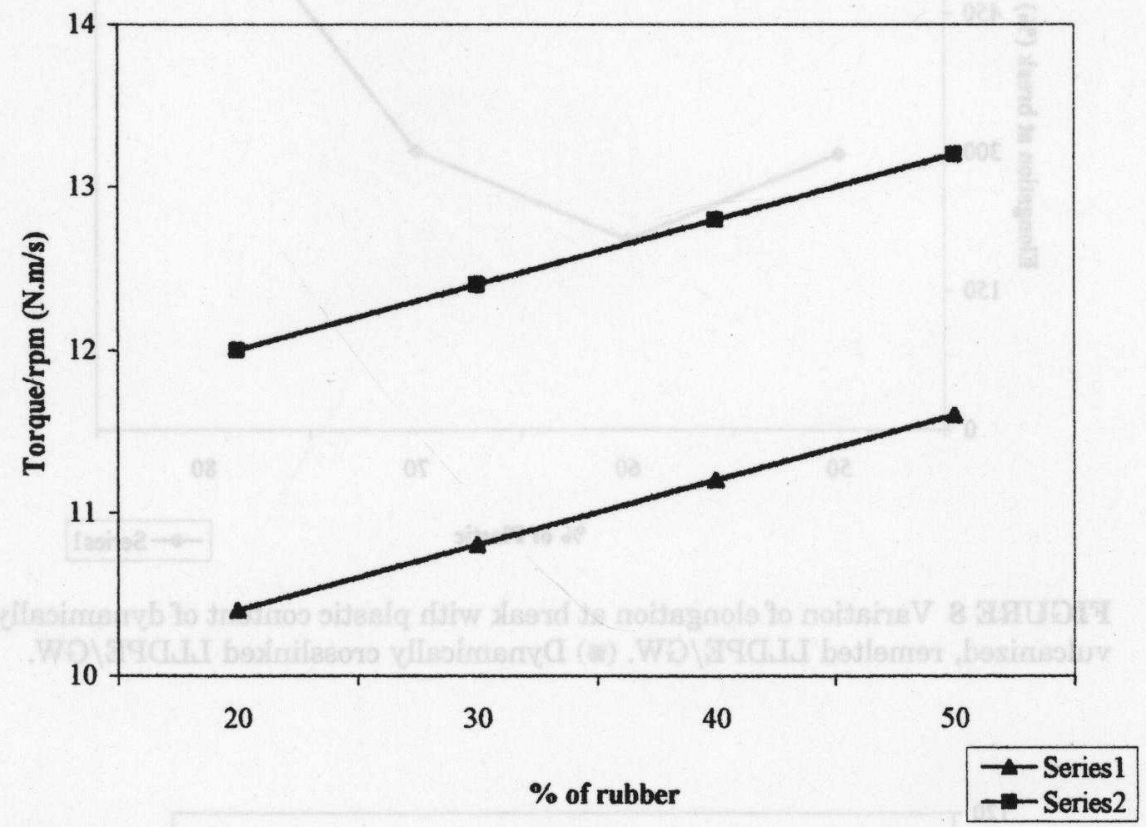

FIGURE 10 Variation of torque/rpm (Viscosity) with rubber content of LLDPE/GW. (৯) Uncrosslinked LLDPE/GW (₫) Dynamically crosslinked LLDPE/GW.

As the rubber content increases, permanent set decreases. On crosslinking the rubber phase dynamically, the permanent set values decrease significantly.

Figure 7 gives the variation of tensile strength values of dynamically vulcanized, remelted, and remolded samples, with rubber content. The tensile strength is not much affected by remelting and the reason may be the dynamic vulcanization, which prevented the degradation of the rubber phase during remelting and remolding.

In Figure 8 the elongation at break of remelted samples are plotted against plastic content. The values are very close to the original ones because the extent of crosslinking of rubber phase is retained even after remelting due to dynamic vulcanization.

Figure 9 shows the variation of tear strength with rubber content. Again the values are comparable with those of the original ones. The impact strength measurements have shown values above $1 \mathrm{KJ} / \mathrm{m}$ for all the blends with LLDPE.

Figure 10 shows the variation of viscosity (torque/rpm) with rubber of LLDPE/GW blends, both uncrosslinked and dynamically 


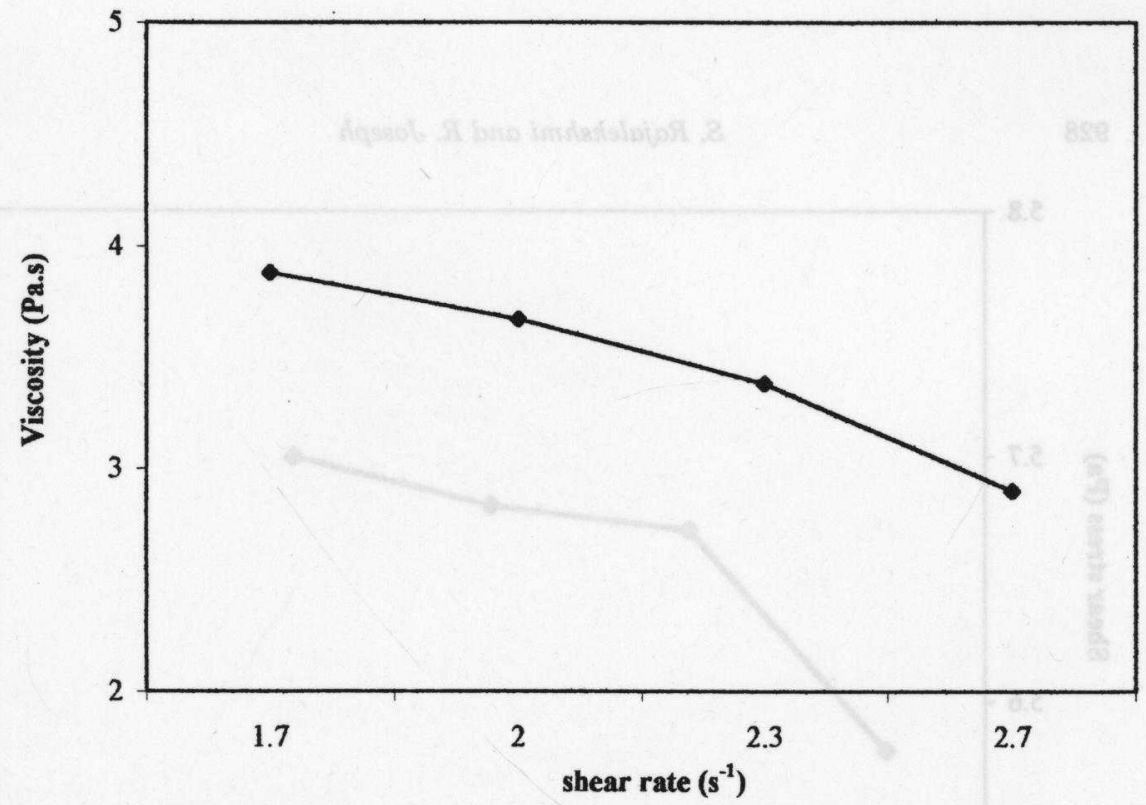

FIGURE 11 Variation of viscosity with shear rate of 50/50 LLDPE/GW, dynamically vulcanized.

crosslinked, measured on the Brabender Plasticorder model PL 3S at constant shear rate of $50 \mathrm{rpm}$. It is seen in both cases that as the rubber content increases. Viscosity also increases. Viscosity values of dynamically vulcanized blends are found to be higher than those of uncrosslinked blends. This is because of the higher torque developed during dynamic vulcanization.

In Figure 11 apparent viscosity is plotted against apparent shear rate of 50/50 LLDPE/GW dynamically vulcanized blend, measured on a HAAKE Rheoflixer V3.53. It is seen that as the shear rate increases viscosity decreases. This shows that the blend is pseudo plastic in nature [22].

Figure 12 shows the variation of shear stress with shear rate of 50/ $50 \mathrm{LLDPE} / \mathrm{GW}$ blend. As the shear rate increases, shear stress also increases as expected. This confirms the non-Newtonian behavior of the blend.

Figure 13 shows the variation of viscosity and shear stress with shear rate of 80/20 LLDPE/GW dynamically vulcanized blend, measured on the capillary viscotester. The same trends as that of 50/50 blend are shown here also; that is, as the shear rate increases, 


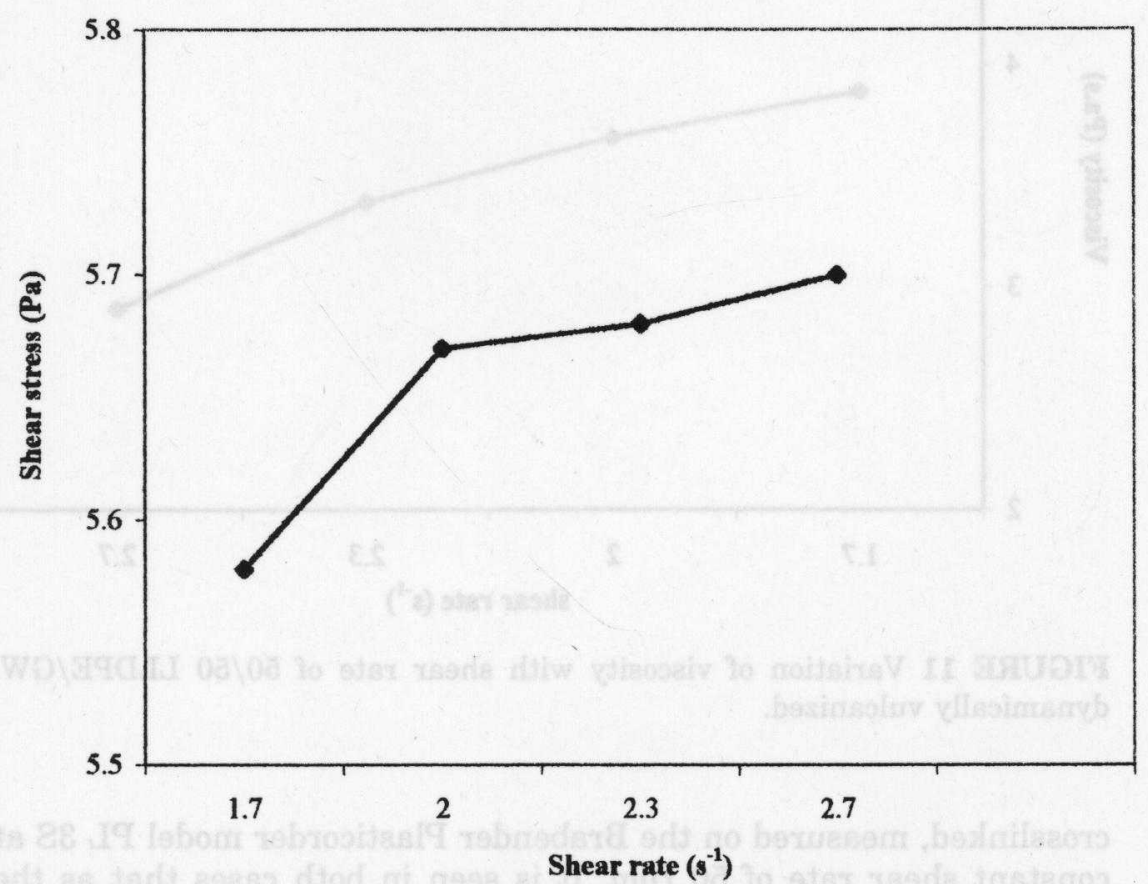

FIGURE 12 Variation of shear stress with shear rate of 50/50 LLDPE/GW, dynamically vulcanized.

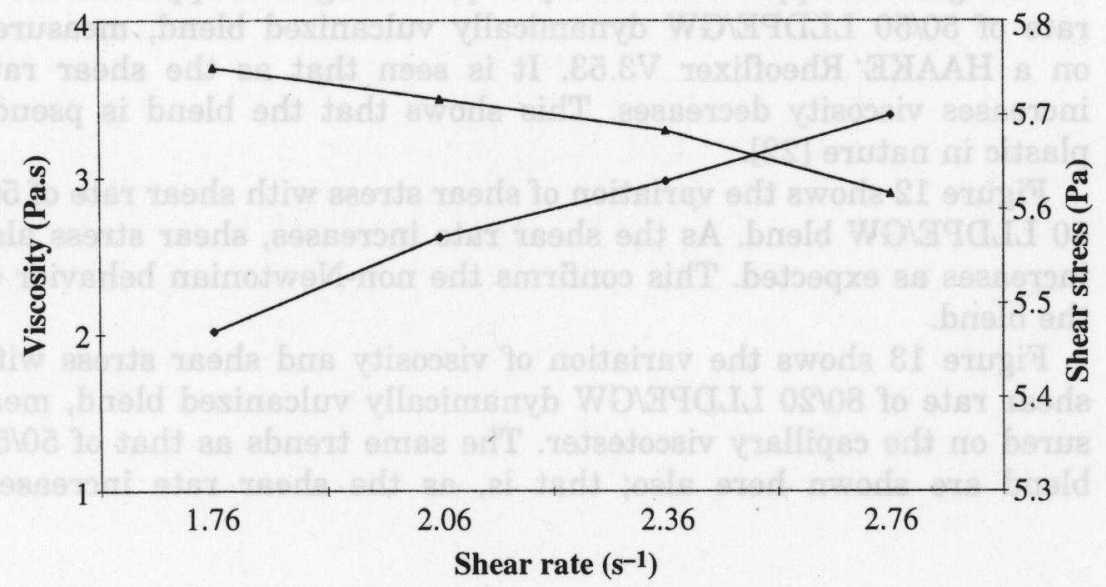

FIGURE 13 Variation of viscosity and shear stress with shear rate of $80 / 20$ LLDPE/GW, dynamically vulcanized. 
Shear rate $\left(s^{-1}\right)$
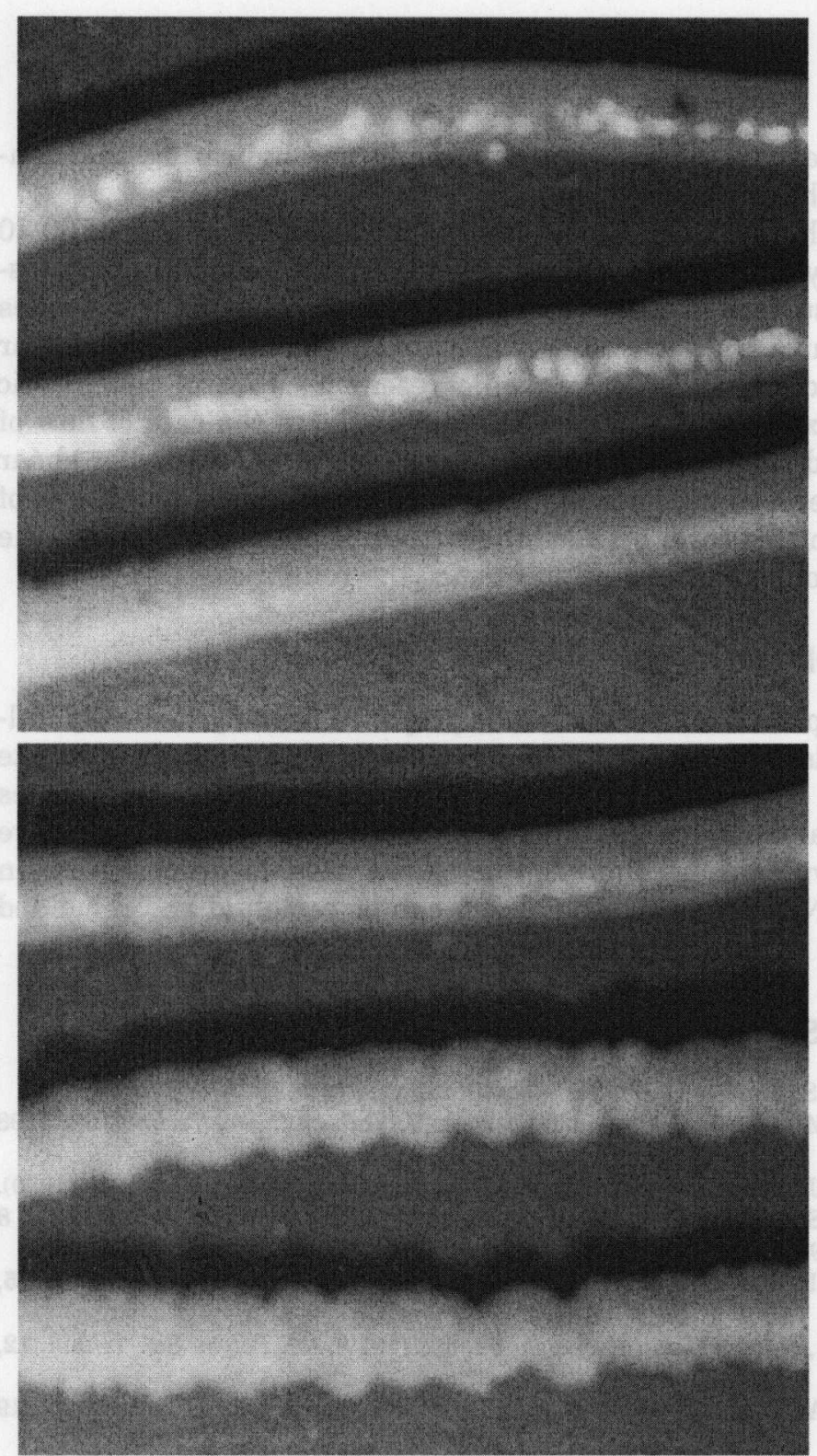

0.1

0.5

0.2

1.0

1.5

FIGURE 14 Optical photographs of extrudates of 80/20 LLDPE/GW, dynamically vulcanized blends from capillary rheometer. 
viscosity decreases and shear stress increases, indicating the nonNewtonian behavior of the blend.

Figure 14 shows the optical photographs of the extrudates of 80/20 LLDPE/GW dynamically vulcanized blend, from the capillary viscotester. A rough surface is observed for extrudates at higher shear rates and smooth surface at lower shear rates. In this blend, at higher shear rates, the viscosity-shear rate profile resembles that of the plastic material, as expected [23]. There is a difference in the rate of flow of the plastic and rubber phases at various shear rates. At higher shear rates this difference becomes higher and results in more roughness of the surface. In this case, because the rubber phase is crosslinked, the difference becomes significant and hence the roughness also.

\section{CONCLUSION}

Novel thermoplastic elastomer can be prepared from dynamically vulcanized blends of linear low-density polyethylene and glove waste modified with thiocarbanilide. It exhibits good mechanical properties and rheological behavior. All other blends of LLDPE/GW, which were dynamically vulcanized, show better or comparable properties than with LLDPE/NR blends. All the blends can be remelted and remolded without much deterioration in properties.

\section{REFERENCES}

[1] Le Beau, D. S., Rubber Chem. Technol. 40, 217 (1967).

[2] Norling, P. M., Lee, T. C. P., and Tobosky A. V., Rubber Chem. Technol. 38, 1198 (1965).

[3] Swor, R. A., Jensen, L. W., and Budsol, M., Rubber Chem. Technol. 53, 1215 (1980).

[4] Yamashita, S., Nippon Gomu Kyokaishi 6, 357 (1981); Int. Polym. Sci. Technol. 8 (12), T/77 (1981).

[5] Grane, G., Elefritz, R. A., Kay, E. L., and Laman, J. R., Rubber Chem. Technol. 5, 577 (1978).

[6] Tomihisa, K., Nippon Gomu Kyokaishi 52, 308 (1979); Int. Polym. Sci. Tehnol. 12, 31 (1979).

[7] Phadke, A. A., Chakraborty, S. R., and De, S. K., Rubber Chem. Technol. 57, 19 (1984).

[8] Chopey, N. P., Chem. Eng. 80, 54 (1973).

[9] Wolk, R. H., Rubber Age 104, 103 (1972).

[10] Phadke, A. A. and Bhowmick, A. K., J. Appl. Polym. Sci. 32 (4), 4063 (1986).

[11] Kresge, E. N. J. Appl. Polym. Sci. 39, 37 (1984).

[12] Coran, A. Y. (1987). In Thermoplastic Elastomers. N. R. Legge, G. Holden and H. E. Schroeder, Eds., Hanser, New York, Chapter 7.

[13] Wolfe, Jr. J. R. (1987). In Thermoplastic Elastomers. N. R. Legge, G. Holden and H. E. Schroeder, Eds., Hanser, New York, Chapter 6.

[14] Rader, C. P. (1988). In Hand Book of Thermoplastic Elastomers. B. M. Walker and C. P. Rader, Eds. Van Nostrand Reinhold, New York, Chapter 4. 
[15] Walker, B. M. (1979). In Hand Book of Thermoplastic Elastomers. Van Nostand Reinhold, New York.

[16] Coran, A. Y. and Patel, R. P., Rubber Chem. Technol. 53, 141 (1980).

[17] Coran, A. Y. and Patel, R. P., Rubber Chem. Technol. 53, 781 (1980).

[18] Coran, A. Y., Patel, R. P., and Williams, D., Rubber Chem. Technol. 55, 116 (1982).

[19] Coran, A. Y. (1988). In Hand Book of Elastomers, A. K. Bhowmick and Howard L. Stephens, Eds., Marcel Decker Inc. New York, pp.249-310.

[20] Coran, A. Y. (1987). Thermoplastic Elastomers, N. R. Legge, G. Holden and H. E. Schroeder, Eds., Hanser, New York, Chapter 7.

[21] Chen, Zhanxun, Wang, et al., Gaofenzi Cailiao Kexue Yu Gongcheng 7, 3, (1991).

[22] Akhtar, S. et al., Plastics and Rubber Processing and Appl. 7, 11-18 (1987).

[23] Coran, A. Y. (1987). In Thermoplastic Elastomers, N. R. Legge, G. Holden and H. E. Schroeder, Eds., Hanser, New York, Chapter 7, p 157. 